\title{
Lignite oxidative desulphurization
}

\author{
Notice 1. Process condition selection
}

\author{
Volodymyr Gunka · Serhiy Pyshyev
}

Received: 12 November 2013/Revised: 26 December 2013/Accepted: 26 December 2013/Published online: 12 September 2014 (C) The Author(s) 2014. This article is published with open access at Springerlink.com

\begin{abstract}
The process of lignite desulphurization via its treatment by an oxidant (air or air-steam mixture) has been studied. The research objective was useful determination of steam application in oxidative lignite desulphurization. It has been proved that the water steam should be included in the oxidant composition to increase the hydrogen sulphide and combustible constituent content in the gases obtained during the processes under research. The impact of factors which affect the reactions between solid (in our case - lignite) and gaseous reagent (oxidant, i.e. air and or air-steam mixture) upon the research process has been investigated, if these reactions occur in the kinetic area. Such factors are linear rate of oxidant movement and coal grain size. The values of oxidant movement linear rate and coal grain size, which the reaction transfer from pyrite sulphur and organic content of lignite from diffusion into kinetic area occurs by, have been determined. Under these "transfer" conditions, the values of coefficients of oxidant mass transfer $(\beta, \mathrm{m} / \mathrm{s})$ as well as Sherwood criteria and boiling layer differences have been calculated.
\end{abstract}

Keywords Lignite $\cdot$ Oxidative desulphurization $\cdot$ Pyrite $\cdot$ Sulphur $\cdot$ Hydrogen sulphide

\section{Introduction}

The coal is a feedstock for the production of $30.3 \%$ of primary energy (hard coal $-28.5 \%$ and lignite $-1.8 \%$ ) and $42 \%$ of the electric power in the world. In 2011, the coal was the most rapidly increasing type of non-recoverable energy; its part in the power engineering is growing constantly. Such tendency is caused by the considerable coal reserves exceeding other reserves of non-recoverable energy sources (Table 1).

In compliance with the data of the Table 1 and according to today's level of oil extraction, its reserves will be sufficient for 54 years, natural gas - for 58-64 years, coal - for 112-127 years (hard coal - 115, and lignite - 316). Taking into account the predicted reserves and

V. Gunka $(\bowtie) \cdot$ S. Pyshyev

Institute of Chemistry and Chemical Technologies, Lviv

Polytecnic National University, 12 Bandery Str., Lviv 79013,

Ukraine

e-mail:vgunka@gmail.com modern consumption level, the oil may be used for only 115 years, natural gas -235 years, coal $-2,750$ years (hard coal $-2,621$ and lignite $-4,770$ ).

On the other side, using coal in the heat-and-power engineering affects the environment negatively. The main reason is the high sulphur content in the coal, resulting in the emissions of sulphur dioxide. In 2005 more than $50 \%$ of all $\mathrm{SO}_{2}$ emissions in the world were caused by coal burning; in 2008-2009 the stationary sources of heat-andpower production released $68.6 \%-70.2 \%$ of $\mathrm{SO}_{2}$.

Today we lack the information on industrial technology of coal desulphurization before its burning. There are some methods of waste gases purification based on $\mathrm{SO}_{2}$ absorption or deposition by chemically active sorbents. The calcium compounds are prevailing among the sorbents and gypsum is the end product.

The aforementioned methods have a series of essential disadvantages

(1) Only $30 \%-50 \%$ of obtained materials (primarily, gypsum) are used as a secondary feedstock (in building products); other $50 \%-70 \%$ settle over 
Table 1 The structure of reserves and extraction of fossil fuels in the world

\begin{tabular}{|c|c|c|c|c|c|c|c|c|}
\hline \multirow[t]{2}{*}{ Fuel } & \multicolumn{2}{|l|}{ Reserves (\%) } & \multirow{2}{*}{$\begin{array}{l}\text { Production } 2011 \\
(P), P=494 \mathrm{EJ}(\%)^{\mathrm{a}}\end{array}$} & \multirow{2}{*}{\multicolumn{2}{|c|}{$\begin{array}{l}R / P \text { ratio }^{\mathrm{b}} \\
\text { (year) }\end{array}$}} & & \multirow{2}{*}{\multicolumn{2}{|c|}{$\begin{array}{l}E / P \text { ratio }^{\mathrm{b}} \\
\text { (year) }\end{array}$}} \\
\hline & $\begin{array}{l}\text { Proved }(R), \\
R=9459 \mathrm{EJ}^{\mathrm{a}}\end{array}$ & $\begin{array}{l}\text { Estimated }(E), \\
E=532,090 \mathrm{EJ}^{\mathrm{a}}\end{array}$ & & & & & & \\
\hline Hard coal & 47.4 & 79.8 & 32.8 & 115 & 127 & 112 & 2621 & 2750 \\
\hline Lignite & 8.3 & 9.3 & 2.1 & 316 & & & 4770 & \\
\hline Uranium & 2.7 & 1.2 & 5.5 & 39 & & & 235 & \\
\hline Thorium & & 0.5 & & & & & & \\
\hline Conv. crude oil & 17.8 & 1.2 & 33.8 & 54 & & 54 & 115 & \\
\hline Non-conv. crude oil & 5.1 & 2.4 & & & & & & \\
\hline Conv. natural gas & 18.3 & 2.2 & 25.7 & 58 & & 64 & 235 & \\
\hline Non-conv. natural gas & 0.4 & 3.4 & & & & & & \\
\hline Total & 100 & 100 & 100 & 80 & & & 1078 & \\
\hline
\end{tabular}

a Exajoule $(\mathrm{EJ})=10^{18} ;$ Joule $=34.1 \times 10^{6}($ tons $) ;$ coal equivalent $=23.9 \times 10^{6}$ (tons); oil equivalent $=26.3 \times 10^{9}\left(\right.$ natural gas, $\left.\mathrm{m}^{3}\right)$

b http://www.bgr.bund.de

refuse tips (http://www.sourcewatch.org; Pasini and Walker 2012);

(2) The average cost of energy block reconstruction with the arrangement of new electric filters and mounts for sulphur (IV) oxide removal from smoke fumes ranges from 240-340 (Gusar 2010) to 400-600 (Nechaeva 2011) dollars per $1 \mathrm{~kW}$ (power);

(3) Smoke fumes adsorptive systems may decrease energy block efficiency by $1.5 \%-5.0 \%$ and demand high operating costs (from 3 to 8 millions euro per year) (Podda 2009; Johansson 2009).

One of the methods of sulphur removal from the coal is its desulphurization via oxidative method (Hayvanovych and Pyshyev 2003; Pyshyev et al. 2004, 2007, 2012). The process lies in processing the feedstock by the air-steam mixture, at that the pyritic sulphur that is the main part of the total sulphur in the coal is selectively converted. The main products are solid low-sulphuric fuel; tar formed during organic thermal decomposition; desulphurization gases with high sulphur content (compared with gases of heat-and-power stations) that makes it possible to utilize or treat them by known methods (Grunvald 1992; Javorskyi 2010); sulphur, sulphuric acid, etc. The suggested process may be the first stage of two-staged burning of the coal at heat-and-power stations (Hayvanovych and Pyshyev 2003).

In our previous studies (Hayvanovych and Pyshyev 2003; Pyshyev et al. 2004, 2007, 2012), we thoroughly examined oxidative desulphurization of the hard coal. It was shown that desulphurization of hard coal and lignite has the essential differences, i.e. during the treatment by air-steam mixture or by air, the sulphur in hard coal converts into sulphur dioxide and sulphur in lignite - into hydrogen sulphide (Pyshyev et al. 2012).
The lignite desulphurization was not studied in details. Therefore, in the paper we determined the high-sulphuric lignite desulphurization conditions and optimal parameters of the process. The first part of investigation deals with the choice of process conditions. We established the advisability of water steam addition to the air and determined fluidized bed parameters ensuring the proceeding of the reaction between an oxidant and sulphur (coal) in the kinetic area under the predicted optimal temperature.

\section{Experimental}

The lignite for investigations was sampled at Morozivske coal-field of Dnipro lignite basin. The coal sample was grinded and sifted by grain size. For all coal fractions technical analysis was carried out and different sulphur forms such as organic sulphur $\left(S_{\mathrm{o}}^{\mathrm{d}}\right)$, pyritic sulphur $\left(S_{\mathrm{p}}^{\mathrm{d}}\right)$ and sulphate sulphur $\left(S_{\mathrm{SO}_{4}}^{\mathrm{d}}\right)$ were determined. The results are given in Table 2.

The scheme of investigations is represented in Fig. 1 The detailed description of the laboratory plant is given in (Pyshyev and Hayvanovych 1996).

The desulphurization gases were analyzed by means of gas-adsorptive chromatography, using chromatographs LHM (N 479) (Pyshyev et al. 2007, 2012).

To characterize the relative rate of sulphuric compounds conversion, we used the term "total sulphur conversion (TSC)". This value indicated the amount of sulphur converted into gaseous sulphur-containing products that will not be in the atmosphere while further burning of desulphurized coal (the level of environmental pollution decrease). It is calculated in accordance with the formula (1), \%: 
Table 2 Characteristics of brown coal fractions

\begin{tabular}{|c|c|c|c|c|c|c|c|}
\hline \multirow[t]{2}{*}{ Fraction $(\mathrm{mm})$} & \multirow{2}{*}{$\begin{array}{l}\text { Moisture, } \\
W^{\text {af }}(\text { mass \%) }\end{array}$} & \multirow{2}{*}{$\begin{array}{l}\text { Ash, } A_{\mathrm{d}} \\
(\text { mass } \% \text { ) }\end{array}$} & \multirow{2}{*}{$\begin{array}{l}\text { Volatiles, } \\
V_{\text {daf }}(\text { mass \%) }\end{array}$} & \multicolumn{4}{|c|}{ Sulphur content (mass \%) } \\
\hline & & & & Total $S_{\mathrm{t}}^{\mathrm{d}}$ & Pyritic $S_{\mathrm{p}}^{\mathrm{d}}$ & Organic $S_{\mathrm{o}}^{\mathrm{d}}$ & Sulphate $S_{\mathrm{SO}_{4}}^{\mathrm{d}}$ \\
\hline For 0.1 & 12.64 & 9.89 & 63.02 & 4.34 & 1.88 & 2.36 & 0.10 \\
\hline $0.1-0.25$ & 13.96 & 9.42 & 63.78 & 4.28 & 2.10 & 2.06 & 0.11 \\
\hline $0.25-0.315$ & 14.03 & 9.16 & 64.34 & 4.31 & 1.97 & 2.20 & 0.13 \\
\hline $0.315-0.5$ & 14.02 & 9.25 & 64.83 & 4.25 & 1.80 & 2.23 & 0.22 \\
\hline $0.5-0.75$ & 13.49 & 9.16 & 66.77 & 4.25 & 1.71 & 2.36 & 0.17 \\
\hline $0.75-1.00$ & 13.51 & 9.44 & 66.90 & 4.36 & 1.81 & 2.37 & 0.17 \\
\hline $1.00-1.60$ & 13.44 & 9.25 & 67.34 & 4.38 & 1.92 & 2.27 & 0.19 \\
\hline $1.60-2.00$ & 13.43 & 8.62 & 66.60 & 4.53 & 1.64 & 2.64 & 0.25 \\
\hline
\end{tabular}

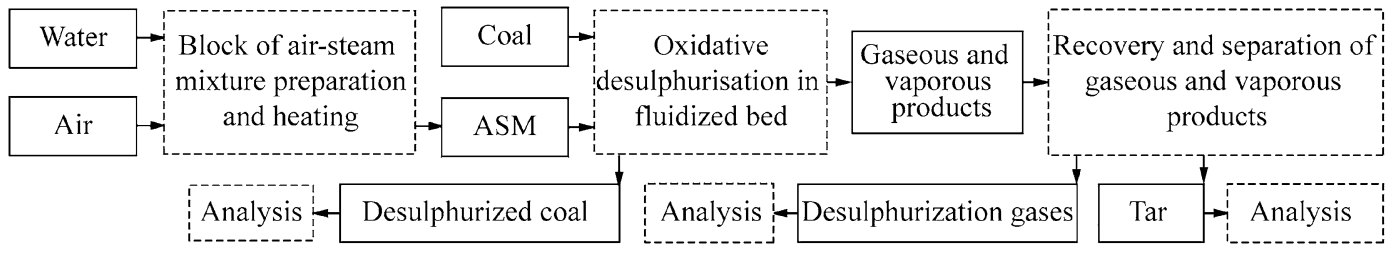

Fig. 1 Flowchart of the laboratory plant for coal oxidative desulphurization

$T S C=\frac{100 S_{\mathrm{t} 0}^{\mathrm{a}}-S_{\mathrm{t}}^{\mathrm{a}} x_{C}}{S_{\mathrm{t} 0}^{\mathrm{a}}}$

where $S_{\mathrm{t} 0}^{\mathrm{a}}$ - the content of total sulphur in the initial coal relative to the analytical sample, mass $\% ; S_{\mathrm{t}}^{\mathrm{a}}-$ the content of total sulphur in the desulphurized coal relative to the analytical sample, mass $\% ; x_{C}$ - the yield of desulphurized coal, mass $\%$.

The sulphur content in the desulphurized coal depends on the ratio between the conversion rates of the coal and pyritic sulphur in it. Hence, the removal degree of pyritic sulphur (RDPS) is calculated in accordance with the formula (2) and indicates the ratio between the rate of $\mathrm{FeS}_{2}$ conversion followed by the production of gaseous products and the rate of organic matter reaction, i.e. process selectivity:

$R D P S=100 \frac{S_{\mathrm{p} 0}^{\mathrm{d}}-S_{\mathrm{p}}^{\mathrm{d}}}{S_{\mathrm{p} 0}^{\mathrm{d}}}$

where $S_{\mathrm{p} 0}^{\mathrm{d}}$ - the content of pyritic sulphur relative to the dry sample, mass $\% ; S_{\mathrm{p}}^{\mathrm{d}}-$ the content of pyritic sulphur in the desulphurized coal relative to the dry sample, mass $\%$.

The oxidant linear rate (OLR) is calculated as a ratio of oxidant volumetric flow rate $\left(\mathrm{m}^{3} / \mathrm{s}\right.$ under the normal conditions) to sectional area of an empty reactor $\left(\mathrm{m}^{2}\right)$.

To characterize the oxidant consumption, the term "repetition factor of oxidant flow rate" (OFR) was used. OFR was calculated as the ratio between volumetric flow air-steam mixture $\left(\mathrm{m}^{3} / \mathrm{h}\right)$ and coal mass $(\mathrm{kg})$.
While describing conversions occurred with the coal organic matter (COM), we assumed that conversions proceed in three directions, i.e. thermal destruction (decomposition tar is formed); gasification with the formation of combustible gases (hydrogen, hydrocarbons, $\mathrm{CO}$ ); burning $\left(\mathrm{CO}_{2}\right.$ is obtained). The amount of COM necessary for the production of all aforementioned products is characterized by the term "coal organic matter conversion" (CCOM). To characterize the ratio between amount of COM from which combustible products are formed (tar, hydrocarbon gases, carbon (II) oxide) and amount of burned $\mathrm{COM}$ (for $\mathrm{CO}_{2}$ formation), we used the term "efficiency factor of coal organic matter conversion" (EFCCOM).

$$
\begin{aligned}
\text { COMC }= & \frac{V_{\mathrm{dg}}}{22.4 m_{\mathrm{C}}}\left(x_{\mathrm{CH}_{4}} M_{\mathrm{CH}_{4}}+x_{\mathrm{C}_{2}-\mathrm{C}_{3}} M_{\mathrm{C}_{2}-\mathrm{C}_{3}}\right. \\
& \left.+x_{\mathrm{CO}} M_{\mathrm{CO}}+x_{\mathrm{CO}_{2}} M_{\mathrm{CO}_{2}}\right)+x_{\mathrm{t}}
\end{aligned}
$$

COMC

$$
=\frac{\frac{V_{\mathrm{dg}}}{22.4 m_{\mathrm{C}}} \cdot\left(x_{\mathrm{CH}_{4}} M_{\mathrm{CH}_{4}}+x_{\mathrm{C}_{2}-\mathrm{C}_{3}} M_{\mathrm{C}_{2}-\mathrm{C}_{3}}+x_{\mathrm{CO}} M_{\mathrm{CO}}\right)+x_{\mathrm{t}}}{\frac{V_{\mathrm{dg}}}{22.4 m_{\mathrm{C}}} x_{\mathrm{CO}_{2}} M_{\mathrm{CO}_{2}}}
$$

where $x_{\mathrm{CH}_{4}}, x_{\mathrm{C}_{2}-\mathrm{C}_{3}}, x_{\mathrm{CO}}, x_{\mathrm{CO}_{2}}-$ the concentrations of corresponding components in the desulphurization gases, vol \%; $M_{\mathrm{CH}_{4}}, M_{\mathrm{C}_{2}-\mathrm{C}_{3}}, M_{\mathrm{CO}}, M_{\mathrm{CO}_{2}}$ - the molecular masses of methane, $\mathrm{C}_{2}-\mathrm{C}_{3}$ the mixture and carbon, respectively; $V_{\mathrm{dg}}$ - the volume of desulphurization gases, $\mathrm{m}^{3} ; m_{\mathrm{C}}-$ the initial coal mass, $\mathrm{kg} ; x_{\mathrm{t}}-$ the tar yield, mass $\%$. 
To characterize the physical parameters of oxidant external mass transfer to the coal grains and pyrite, we used the term "mass transfer coefficient"; the intensity of fluidized bed - "fluidized bed porosity".

Mass transfer coefficient per unit of external surface of phase contact was calculated in accordance with (Todes and Cytovych 1981):

$\beta=\frac{S h \cdot D}{d}$

where $S h$ - Sherwood criterion (diffusion Nusselt number); $D$ - the diffusion coefficient of the gas phase, $\mathrm{m}^{2} / \mathrm{s} ; d-$ the average size of coal grain, $\mathrm{m}$.

$S h=0.01 S c^{\frac{1}{3}} \frac{R e}{\varepsilon}$

where $S \mathrm{c}-$ Schmidt criterion (diffusion Prandtl number); $R e$ - Reynolds criterion.

$R e=\frac{W^{\prime} d}{v}$

$S \mathrm{c}=\frac{v}{D}$

where $W^{\prime}$ - the oxidant linear rate (OLR) in the reactor free area under the operating conditions, $\mathrm{m} / \mathrm{s} ; v$ - the kinematic viscosity of the gaseous reagent, $\mathrm{m}^{2} / \mathrm{s}$.

The fluidized bed porosity was calculated in accordance with the formula (9):

$\varepsilon=\left(\frac{18 R e+0.36 R e^{2}}{A \mathrm{r}}\right)^{0.21}$

where $\mathrm{Ar}$ - Archimedean criterion

$A r=\frac{d^{3} g\left(\rho^{\prime}-\rho\right)}{\rho v^{2}}$

where $\rho$ - the density of gaseous reagent, $\mathrm{kg} / \mathrm{m}^{3} ; g-$ the acceleration of gravity, $\mathrm{m} / \mathrm{s}^{2} ; \rho^{\prime}-$ the apparent density of the solid reagent, $\mathrm{kg} / \mathrm{m}^{3}$.

For the convenience of data processing, OLR was calculated under the normal conditions per the sectional area of an empty reactor. Taking this into account, the reaction pressure was close to the atmospheric one, the value $W^{\prime}$ was calculated in accordance to the formula (11):

$W^{\prime}=\frac{W(273+t)}{273}$

where $W-$ the OLR under the normal conditions; $t$ - the process temperature, ${ }^{\circ} \mathrm{C}$.

All parameters of the gaseous reagent in the formulas (5)-(10) were assumed and calculated under the operational conditions in accordance with the references (Khimiya 1968; Vagraftuk 1972; Pavlov et al. 1987).

\section{Results and Discussion}

While desulphurization of the hard coal, it was established that water steam added to the oxidant (air) stimulates the pyrite conversion and retards COM burning (Pyshyev et al. 2007, 2012). On the other hand, the analytic sample of the lignite already contains 12,014 mass $\%$ of moisture in it. Therefore, it was necessary to check an expediency of water steam used while the lignite desulphurization.

It is well-known that the coal is a solid porous matter, which inside coal exceeds the outsides by several times (Sklyar and Tutunykov 1985). Thus, the main part of pyrite reacted with the oxidant is situated in the coal volume. Under such conditions, the total rate of heterophase process between solid (coal) and gaseous (oxidant) matters may be determined by the rate of oxidant diffusion to the grain surface (external diffusion area), rate of gases diffusion inside the coal pores (internal diffusion area) and reaction rate (kinetic area).

In the external diffusion area at the constrained motion of gaseous reagent (including fluidized bed), the rate of convective diffusion considerably exceeds the rate of molecular and thermal diffusion, determines the intensity of reagent mass transfer from the volume to the surface of solid matter and equals to the total rate of the process. In the fluidized bed, the mass transfer coefficient $(\beta, \mathrm{m} / \mathrm{s})$ is calculated per unit of phase contact surface and determined by physical and process parameters of gaseous medium and solid compound. The analysis of known dependencies (Eqs. 5-10) confirms that OLR and size of solid particles are those process parameters affecting the total rate of the reaction between gaseous and solid matters in the external diffusion area. The rate of the reactions limited by the diffusion in the solid matter pores is inversely proportional to the solid particles diameter at the sufficient amount of gaseous reagent and its constant concentration (Ioffe 1972). Hence, if we achieve conditions under which OLR and grain size have no influences on the sulphur conversion, we may assert that reactions of sulphur conversion proceed in the kinetic area.

Thus, the second task of the conditions establishment was to determine OLR and grain size values, as well as fluidized bed parameters and mass transfer coefficients depended on the aforementioned values in such a way, that desulphurization reaction should proceed in the kinetic area under maximally possible temperatures.

\subsection{Effect of the oxidant composition}

The results concerning the oxidant composition effect (water steam content in it) on the sulphuric compounds and COM conversion are represented in Table 3 and Figs. 2, 3. 
Table 3 The dependence of desulphurisation gas of lignite on oxidant

\begin{tabular}{|c|c|c|c|c|c|c|c|c|c|c|}
\hline \multicolumn{2}{|c|}{ Content in the oxidant (vol \%) } & \multicolumn{9}{|c|}{ Content (vol \%) } \\
\hline Water steam & Oxygen & $\mathrm{H}_{2}$ & $\mathrm{CH}_{4}$ & $\mathrm{C}_{2}-\mathrm{C}_{3}$ & $\mathrm{H}_{2} \mathrm{~S}$ & $\mathrm{CO}_{2}$ & $\mathrm{CO}$ & $\mathrm{N}_{2}$ & $\mathrm{O}_{2}$ & $\mathrm{Ar}$ \\
\hline 4.5 & 20.1 & 0.29 & 0.62 & 0.77 & 1.89 & 16.45 & 2.41 & 74.92 & 1.78 & 0.87 \\
\hline 30.0 & 14.7 & 0.33 & 0.94 & 0.69 & 2.41 & 16.22 & 2.84 & 72.15 & 3.58 & 0.84 \\
\hline 50.0 & 10.5 & 0.37 & 0.98 & 0.72 & 2.99 & 17.27 & 2.50 & 71.30 & 3.04 & 0.83 \\
\hline 70.0 & 6.3 & 0.43 & 1.18 & 1.04 & 4.64 & 17.75 & 2.76 & 68.04 & 3.37 & 0.79 \\
\hline
\end{tabular}

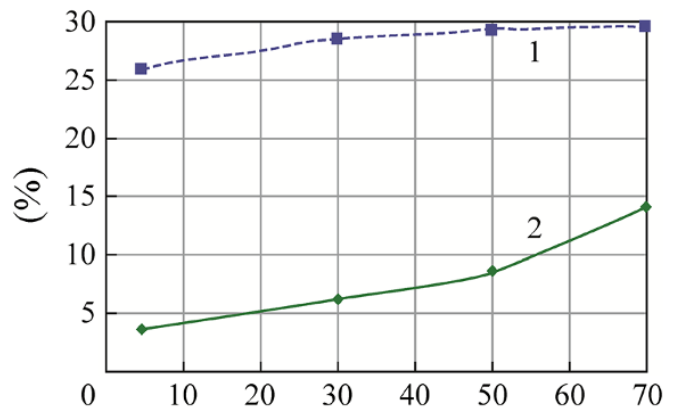

Content of water steam in oxidant (vol \%)

Fig. 2 Dependence of CCOM (1) and EFCCOM (2) of lignite on oxidant content

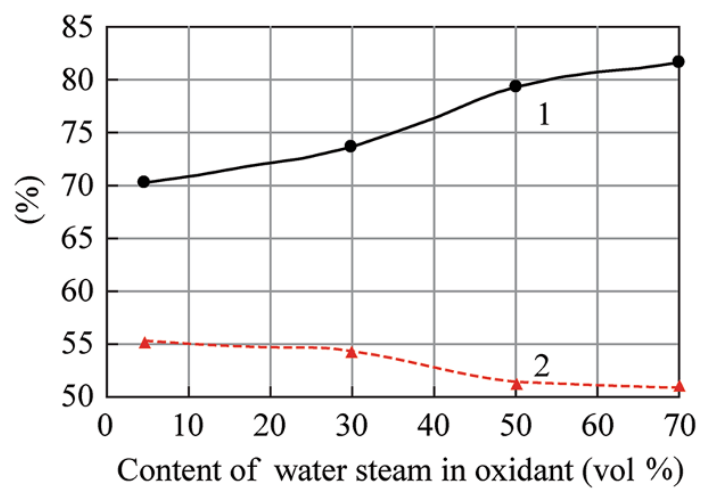

Fig. 3 Dependence of RDPS (1) and TSC (2) of lignite on oxidant content

The increase of water steam amount in the oxidant slightly increases CCOM and considerably increases EFCCOM (Fig. 2). It means that water steam retards the burning of lignite organic matter and insignificantly increases the intensity of its thermal decomposition with organic compounds formation. Hence, the content of unused oxygen in the desulphurization gases is increased (Table 3).

With the increase of water steam content in the oxidant, the sulphur conversion degree is constant and removal degree of total sulphur increases (Fig. 3). Since the amount of converted sulphur is almost the same and volume of desulphurization gases decreases (due to the vapours condensation), the concentration of $\mathrm{H}_{2} \mathrm{~S}$ in the desulphurization gases rises.

Thus, it is advisable to use water steam to increase $\mathrm{H}_{2} \mathrm{~S}$ content in the desulphurization gases, destruction products yield, the yield of organic matter gasification products and combustion heat of desulphurization gases, which will be burned after hydrogen sulphide conversion into sulphur by known methods (Grunvald 1992; Javorskyi 2010).

\subsection{Effect of the oxidant linear rate}

The results concerning the OLR effect are represented in Table 4 and Figs. 4, 5.

The OLR increase leads to the CCOM increase and EFCCOM decrease (Fig. 4). It means that while the lignite desulphurization the OLR increase within the range of $0.006-0.050 \mathrm{~m} / \mathrm{s}$ intensifies the COM oxidation and increases $\mathrm{CO}_{2}$ content in the oxidation gases (Table 4). The increase of OLR above $0.0125 \mathrm{~m} / \mathrm{s}$ causes the oxidation and secondary decomposition of the tar, because concentration of combustible components and carbon (IV) oxide increases in the desulphurization gases. It should be noted that considerable amount of $\mathrm{CO}$ and $\mathrm{CO}_{2}$ is formed due to $\mathrm{COM}$ thermal conversion, because their content is

Table 4 Dependence of gas desulphurisation of OLR

\begin{tabular}{llllllllll}
\hline $\begin{array}{l}\text { Linear } \\
\text { speed } \\
(\mathrm{m} / \mathrm{s})\end{array}$ & \multicolumn{6}{l}{ Content (vol \%) } \\
\cline { 2 - 10 } & $\mathrm{CH}_{4}$ & $\mathrm{C}_{2}-\mathrm{C}_{3}$ & $\mathrm{H}_{2} \mathrm{~S}$ & $\mathrm{CO}_{2}$ & $\mathrm{CO}$ & $\mathrm{N}_{2}$ & $\mathrm{O}_{2}$ & $\mathrm{Ar}$ \\
\hline $0^{\mathrm{a}}$ & 5.07 & 4.66 & 15.68 & 62.07 & 9.86 & $0^{\mathrm{b}}$ & 2.66 & 0 \\
0.00625 & 0.62 & 0.94 & 1.61 & 10.39 & 1.27 & 76.97 & 7.3 & 0.9 \\
0.01250 & 0.79 & 0.41 & 1.72 & 12.97 & 2.08 & 76.06 & 5.08 & 0.89 \\
0.01875 & 0.75 & 0.44 & 1.84 & 14.25 & 2.55 & 75.87 & 3.41 & 0.89 \\
0.02500 & 0.65 & 0.82 & 1.89 & 16.45 & 2.53 & 74.92 & 1.87 & 0.87 \\
0.03750 & 0.74 & 0.85 & 1.76 & 21.36 & 3.28 & 69.08 & 2.12 & 0.81 \\
0.05000 & 0.69 & 1.41 & 1.68 & 23.46 & 3.39 & 66.68 & 1.91 & 0.78
\end{tabular}

${ }^{a}$ Cold system with coal purged with nitrogen and held its rapid heating to the process temperature, OFR $=0 \mathrm{~m}^{3} /(\mathrm{h} \cdot \mathrm{kg})$

b The amount of nitrogen is not taken into account during the gas content calculation 


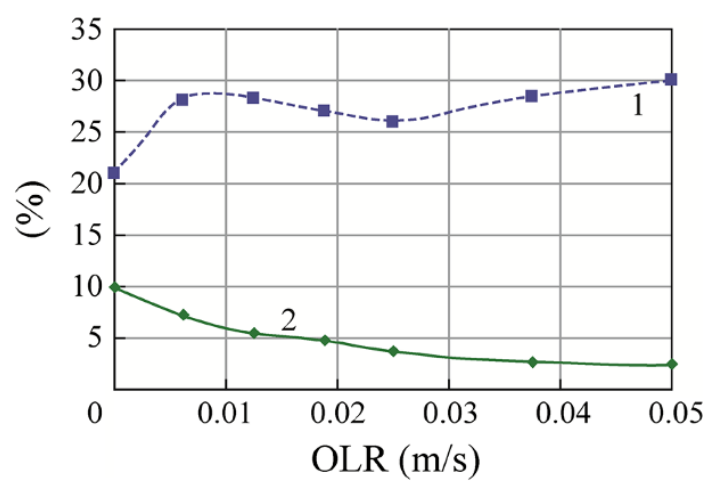

Fig. 4 Dependence of CCOM (1) and EFCCOM (2) of lignite on OLR

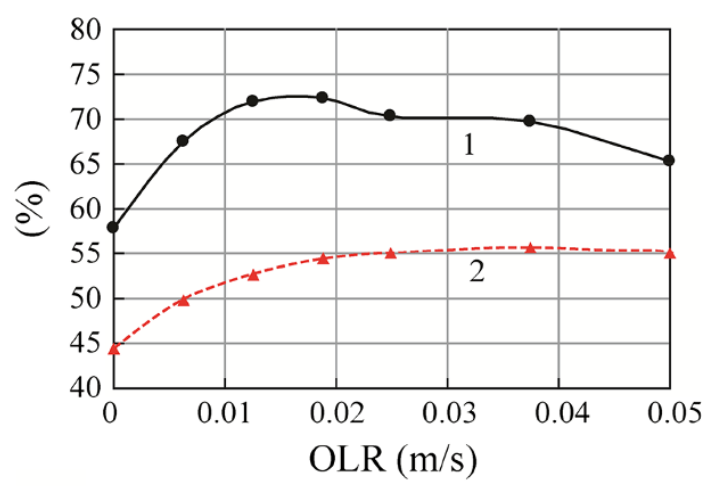

Fig. 5 Dependence of RDPS (1) and TSC (2) of lignite on OLR

maximum (9.86 and 62.07 vol \%, respectively) while feedstock heating without air.

The air supplied into the reaction zone increases the removal degree and sulphur conversion by $5 \%-10 \%$. The further OLR increase has no significant effect on the sulphur conversion intensity (Fig. 5). The reason is that the main part of pyritic sulphur is converted not as a result of interaction with oxygen but due to its reaction with COM (Pyshyev et al. 2012). The high values of sulphur removal degree and conversion as well as the hydrogen sulphide presence in the desulphurization gases at zero air consumption confirm this fact. RDPS indicating the ratio between the rates of sulphur and COM conversion insignificantly increases to $0.01875 \mathrm{~m} / \mathrm{s}$ and then decreases. The TSC value increases to the same value (Fig. 5). Thus, we may assert that at the oxidant rate of $0.01250-0.01875 \mathrm{~m} / \mathrm{s}$ and higher values, the pyrite conversion takes place in the kinetic or internal diffusion areas in the air oxygen presence. Due to the insignificant OLR effect, the removal degree, and sulphur conversion, the content of gaseous product $\left(\mathrm{H}_{2} \mathrm{~S}\right)$ in the desulphurization gases remains constant or even decreases with the increase of linear rate (Table 4). Such reduction of $\mathrm{H}_{2} \mathrm{~S}$ content is explained by the increase in amount of gasification and COM burning products.

To establish the upper limit of the oxidant rate, we carried out experiments at the OLR values higher than maximum ones given in Fig. 4. Since the increase of rate above $0.05 \mathrm{~m} / \mathrm{s}$ affects only COM oxidation and decomposition and does not have influence on the pyrite oxidation, we determined only solid products yield. The obtained results are represented in Table 5.

The increase of OLR above $0.05 \mathrm{~m} / \mathrm{s}$ stimulates COM burning and decomposition. At the COM value of $0.1 \mathrm{~m} / \mathrm{s}$ and higher this impact is practically absent, i.e. COM conversion is not limited by the rate of oxidant motion to the coal grain surface.

\subsection{Effect of coal grain size}

The results obtained during desulphurization of different fractions of the lignite are represented in Table 6 and Figs. 6, 7.

Under the process conditions the intensity of COM conversion slightly depends on coal grain size (Fig. 6), i.e. the main part of COM conversion is not limited by the oxidant diffusion in the coal grains. This tendency is caused by the high reactivity of this type of coal COM

Table 5 Effect OLR on desulphurizated product yield

\begin{tabular}{|c|c|c|c|}
\hline \multirow{2}{*}{$\begin{array}{l}\text { OLR } \\
(W, \mathrm{~m} / \mathrm{s})\end{array}$} & \multicolumn{3}{|l|}{ Yield (mass \%) } \\
\hline & $\begin{array}{l}\text { Desulphurized } \\
\text { coal }\end{array}$ & Tar & $\begin{array}{l}\text { Desulphurized } \\
\text { coal and tar }\end{array}$ \\
\hline 0.050 & 47.77 & 18.03 & 65.80 \\
\hline 0.060 & 47.28 & 17.89 & 65.17 \\
\hline 0.075 & 46.81 & 17.32 & 64.13 \\
\hline 0.100 & 46.03 & 17.41 & 63.44 \\
\hline 0.110 & 46.05 & 17.39 & 63.44 \\
\hline
\end{tabular}

Table 6 The dependence of desulphurisation gas on grain size

\begin{tabular}{|c|c|c|c|c|c|c|c|c|}
\hline \multirow{2}{*}{$\begin{array}{l}\text { Fraction } \\
(\mathrm{mm})\end{array}$} & \multicolumn{8}{|c|}{ Content (vol \%) } \\
\hline & $\mathrm{CH}_{4}$ & $\begin{array}{l}\mathrm{C}_{2^{-}} \\
\mathrm{C}_{3}\end{array}$ & $\mathrm{H}_{2} \mathrm{~S}$ & $\mathrm{CO}_{2}$ & $\mathrm{CO}$ & $\mathrm{N}_{2}$ & $\mathrm{O}_{2}$ & $\mathrm{Ar}$ \\
\hline To 0.1 & 0.89 & 1.06 & 3.24 & 20.42 & 3.22 & 67.06 & 3.33 & 0.78 \\
\hline $0.1-0.25$ & 1.47 & 1.29 & 3.33 & 22.48 & 3.59 & 65.00 & 2.08 & 0.76 \\
\hline $0.25-0.315$ & 1.66 & 1.43 & 3.38 & 23.29 & 4.03 & 63.33 & 2.14 & 0.74 \\
\hline $0.315-0.5$ & 1.87 & 1.83 & 3.44 & 25.22 & 4.47 & 60.21 & 2.26 & 0.70 \\
\hline $0.5-0.75$ & 1.82 & 1.73 & 3.33 & 28.73 & 5.03 & 56.62 & 2.08 & 0.66 \\
\hline $0.75-1$ & 1.43 & 1.65 & 3.29 & 28.13 & 5.39 & 57.42 & 2.02 & 0.67 \\
\hline $1-1.6$ & 1.48 & 1.11 & 3.17 & 26.78 & 6.27 & 58.65 & 1.86 & 0.68 \\
\hline $1.6-2$ & 1.32 & 1.55 & 3.04 & 24.96 & 6.22 & 60.44 & 1.76 & 0.71 \\
\hline
\end{tabular}




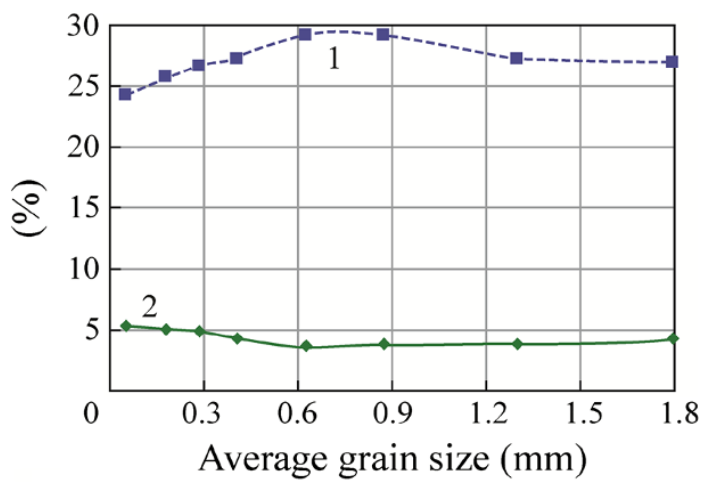

Fig. 6 Dependence of CCOM (1) and EFCCOM (2) of lignite on grain size

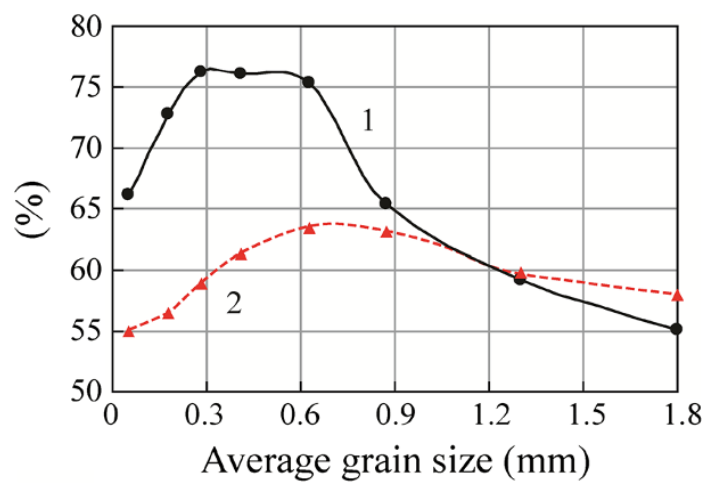

Fig. 7 Dependence of RDPS (1) and TSC (2) of lignite on grain size

capable to convert using its own (organic) oxygen and due to the absence great internal surface (the main part of all reactions proceeds over the surface).

The change of grain size insignificantly affects the sulphur conversion and pyrite in particular. This fact confirms the assumption that reactions between pyrite and COM play the main role while desulphurization of this coal type (Pyshyev et al. 2012). The increase of grain size till $0.315-0.75 \mathrm{~mm}$ we observe the slight increase of sulphur conversion and removal degree. RDPS and TSC decrease using the fractions with grain size of more than $0.75 \mathrm{~mm}$
(Fig. 7). This indicates that minor number of sulphur conversion reactions proceeds using the oxidant (air) and the increase of grain size causes their retardation because these reactions begin to proceed in the internal diffusion area.

Relatively poor results concerning desulphurization of pulverized lignite (fraction till $0.10 \mathrm{~mm}$ ) may be explained by the fact that grain size of this fraction differs by several orders compared with coarser fractions. The organic matter has less hardness and density compared with inorganic one. Therefore, due to the grinding the least (microscopic) coal grains contain the least amount of mineral additives, including pyrite. While the desulphurization of the fraction till $0.10 \mathrm{~mm}$, the "reverse" enrichment takes place; lowash particles are taken out with desulphurization gases and greater particles (with higher sulphur content) remain in the reactor. All this leads to the sulphur conversion decrease and removal degree.

On the basis of the aforementioned investigations, the fluidized bed parameters (porosity), dimensionless criteria and mass transfer coefficient per unit of phase contact external surface $(\beta, \mathrm{m} / \mathrm{s})$ were calculated under the conditions when area changes of the pyrite sulphur and COM conversions take place (Table 7), characterizing the mass transfer intensity of the gaseous reagent (oxygen) to the feedstock grain (coal, pyrite).

Thus, we may assert that Sherwood criterion should be not less than 0.0010 and mass transfer coefficient - higher than $0.0008 \mathrm{~m} / \mathrm{s}$ to provide the sulphur conversion proceeding in the kinetic area with the participation of gaseous reagent. At the same time the grain size and OLR should provide the value of fluidized bed porosity more than 0.6.

In case of the need to increase the COM conversion intensity (in order to rise the reaction temperature, tar yield, etc.), it is advisable to change the process parameters to the level when $S h \approx 0.005 ; \beta \approx 0.004 \mathrm{~m} / \mathrm{s}$. At the same time the porosity approximates to the maximally possible value $(\varepsilon>0.95)$.

The increase of intensity of the gaseous reagent external transfer due to the increase of coal grain size causes the transfer into the internal diffusion area (if there is the

Table 7 The dependence of process stages on the fluidized bed parameters and mass transfer criteria

\begin{tabular}{|c|c|c|c|c|c|c|c|}
\hline Stages & $\begin{array}{l}\text { OLR } \\
W(\mathrm{~m} / \mathrm{s})\end{array}$ & $\begin{array}{l}\text { Average diameter } \\
\text { grain } d(\mathrm{~m})\end{array}$ & $\begin{array}{l}\text { Real OLR } \\
W(\mathrm{~m} / \mathrm{s})\end{array}$ & $\begin{array}{l}\text { Porosity } \\
\varepsilon\end{array}$ & $\begin{array}{l}\text { Reynolds } \\
\text { number } R \mathrm{e}\end{array}$ & $\begin{array}{l}\text { Sherwood } \\
\text { number } S h\end{array}$ & $\beta(\mathrm{m} / \mathrm{s})$ \\
\hline $\begin{array}{l}\text { Transition area of sulphur conversion } \\
\text { reactions }^{\text {a }} \text { (external diffusion-kinetic) }\end{array}$ & 0.0125 & 0.000158 & 0.032 & 0.6141 & 0.0756 & 0.00098 & 0.00082 \\
\hline $\begin{array}{l}\text { Transition area of OMC conversion reactions }{ }^{\mathrm{a}} \\
\text { (kinetic-external diffusion) }\end{array}$ & 0.1000 & 0.000158 & 0.2557 & 0.9525 & 0.6049 & 0.00507 & 0.00422 \\
\hline $\begin{array}{l}\text { Transition area of sulphur conversion } \\
\text { reactions }^{\mathrm{a}} \text { (kinetic-internal diffusion) }\end{array}$ & 0.0250 & 0.000612 & 0.0639 & 0.398 & 0.5856 & 0.01174 & 0.00252 \\
\hline
\end{tabular}

${ }^{a}$ Reaction, involving gaseous reactants 
kinetic area). Such a transfer takes place at the porosity corresponding to the beginning of the fluidized bed formation $(\varepsilon \approx 0.4)$.

\section{Conclusions}

The presence of water steam in the oxidant actually does not affect the intensity of sulphur conversion in the lignite; it only changes the direction of COM conversion. It is advisable to add water steam to the air only to increase $\mathrm{H}_{2} \mathrm{~S}$ content in the desulphurization gases and yields of destruction and gasification products. For instance, in case of use of steam-air mixture that comprises $50 \%$ vol. steam (comparing with air), $\mathrm{H}_{2} \mathrm{~S}$ content in desulphurization gases increases in 1.6. Hereby, the correlation between the number of combustible and non-combustible of steam and gaseous products of the process, which were formed during the process of transfer of organic fuel content (efficiency ratio conversion), increase in twice.

At the values of OLR and grain size provided the mass transfer coefficient per unit of phase contact external surface equal to $0.0008 \mathrm{~m} / \mathrm{s}$ and higher, and porosity is 0.6 , the reactions between the oxidant and pyrite sulphur proceed in the kinetic area.

We recommend to grind the lignite to the size less than $0.5-0.75 \mathrm{~mm}$ (the average diameter is $0.612 \mathrm{~mm}$ ), because the desulphurization of the fraction above $0.75 \mathrm{~mm}$ slightly retards the total rate of the sulphur conversion. It is inexpedient to grind the coal lower than $0.1-0.25 \mathrm{~mm}$ (the average diameter is $0.158 \mathrm{~mm}$ ) because the results are additional energy costs, the decrease of sulphur conversion, and removal degree.

It is for the above parameters necessary to make setting optimum values of the lignite desulphurization factors.

Open Access This article is distributed under the terms of the Creative Commons Attribution License which permits any use, distribution, and reproduction in any medium, provided the original author(s) and the source are credited.

\section{References}

Grunvald V (1992) Technology Sulphur Gas. Khimiya, Moskwa

Gusar MG (2010) Development of measures and feasibility assessments to reduce sulfur oxides emissions in Ukrainian heat power plants. Energetyka ta Elektrofikacija 7:39-42
Hayvanovych V, Pyshyev S (2003) Desulfurization of low-rank coal with high sulfur content is the first stage of coal burning at heat electric station. Energy Fuels 17(5):1186-1190

http://www.sourcewatch.org/index.php?title=Sulfur_dioxide_and_coa l\#Environmental_impacts_of_SO2

http://www.bgr.bund.de/DE/Gemeinsames/Produkte/Downloads/DERA_ Rohstoffinformationen/rohstoffinformationen-15e.pdf?_blob=publi cationFile \& $=3$

Ioffe II (1972) Engineering Chemistry of Heterogeneous Catalysis. Khimiya, Leningrad

Javorskyi VT (2010) The Technology of Sulfur and Sulfuric Acid. Lviv Politechnic, Lviv

Johansson L-E (2009) Choosing NID ${ }^{\circledR}$ DFGD or open spray tower WFGD. Paper presented at European Users Conference, Lisabon, 15-17 September 2009

Khimiya (1968) Handbook of Chemical. Khimiya, Leningrad

Nechaeva TP (2011) Investigation of possible strategies of the electricity sector structure in Ukraine in view of the impact of environmental constraints and requirements. Gen Power Eng Probl 2(25):25-31

Pasini R, Walker HW (2012) Estimating constituent release from FGD gypsum under different management scenarios. Fuel 95:190-196

Pavlov KF, Romankov PG, Noskov AA (1987) Examples and Problems at The Rate of Processes and Devices of Chemical Technologies. Khimiya, Leningrad

Podda E (2009) Project experience and design initiatives. Paper presented at European Users Conference, Lisabon, 15-17 September 2009

Pyshyev S, Hayvanovych V (1996) Laboratory plant of coal desulphurization via oxidation method. Sci Present Lviv Polytech State Univ 298:96-98

Pyshyev S, Gayvanovych V, Pattek-Janczyk A, Stanek J (2004) Oxidative desulphurissation of sulphur-rich coal. Fuel 83:1117-1122

Pyshyev S, Shevchuk K, Cmielarz L, Kustrovski P, Pattek-Janczyk A (2007) Effect of water-vapor content on the oxidative desulfurization of sulfur-rich coal. Energy Fuel 21:216-221

Pyshyev S, Gunka V, Prysiazhnyi Y, Shevchuk K, Pattek-Janczyk A (2012) Study of oxidative desulphurization process of coal with different metamorphism degrees. J Fuel Chem Technol 40(2):13-129

Sklyar MH, Tutunykov YB (1985) Chemistry of Solid Fuels. Vyscha skola, Kyiv

Todes OM, Cytovych OB (1981) Apparatus Fluidized Granular Bed. Khimiya, Leningrad

Vagraftuk NB (1972) Handbook of Thermo-physical Properties of Gases and Liquids. Nauka, Moskva 